\title{
A Tri-Level Industry-Focused Learning Approach for Software Engineering Management
}

\author{
Anis Zarrad \\ College of Computer Science and Information Systems \\ Prince Sultan University, Riyadh 11586, KSA \\ Riyadh, KSA
}

\author{
Yassin Daadaa \\ College of Computer and Information Sciences \\ Al Imam Mohammad Ibn Saud University (IMSIU) \\ Riyadh, KSA
}

\begin{abstract}
Most engineering classes in higher education rely heavily on the traditional lecture format, despite the fact that a number of investigations have shown that lectures, even when given by good lecturers, have limited success in helping students make sense of the engineering practices they are learning. Recently, the Software Engineering Body of Knowledge (SWEBOK) highlighted the importance of professional practice in producing high quality engineering programs. The integration of industry links in teaching pedagogy is essential. In this paper, the authors introduce a new industry-oriented tri-level teaching approach in order to offer students the opportunity to be involved in industry projects and gain important work experience during the academic period. To prioritize industry hands-on activities for students and shape the traditional classroom toward an industry environment, three entities are involved in this approach: industry guest speakers, teachers, and students. Traditionally, guest lecturing is centered on the speaker, who delivers a presentation and follows with a short question and answer session. Students are often passive learners in this process. A blended learning approach was therefore integrated between all entities to allow more flexible learning opportunities, wherein students participated in each step of guest lecturing, including preparation, questions, and reflection. A software project management case study was introduced to measure students' performance and satisfaction.
\end{abstract}

Keywords-Component; software project management; education; student rubric assessment; student learning outcomes; industry activities; guest lecturing approach

\section{INTRODUCTION}

Since the introduction of computers in the 1940s, the use of software has grown dramatically and has become one of the most important fields in the manufacturing industry. The software engineering (SE) discipline was first introduced in 1968, at the NATO Conference on Software Engineering [15]. Despite more than fifty years of effort made to develop various teaching theories, support tools, and practical SE, the SE field continues to lack direction and effective teaching methods.

Most students find it difficult to understand and retain software development processes. The discipline is typically taught using traditional teaching methods, where students must attend lecture classes that are followed by discussion and questions. We feel that using traditional teaching approaches, such as case studies [8], [9], teacher-centered methods [7], and student-centered methods [7], makes it quite difficult for students to understand software development obstacles and the management aspect in such a short duration. Engineers must be practical, but cost and logistics act as barriers to providing undergraduate and graduate engineering students at universities with practical industry experiences. The long time-frames of major real engineering projects and the higher associated cost result in students only seeing a snapshot of the entire project life cycle. Recent trends in SE education recommend that SE students acquire knowledge in both software development and its management. It is necessary that the project should. In this work, we focus on software project management (SPM).

Currently, most SPM teaching techniques involve teachercentric classrooms, as presented in many course specifications [1]-[5]. Challenges exist in teaching a SPM course, as it may be uninteresting and frustrate students when taught theoretically [23], especially when using the traditional approach. The traditional approach uses a one-way information flow in a closed classroom environment, keeping information transfer in the low levels of Bloom's taxonomy (Fig. 1).

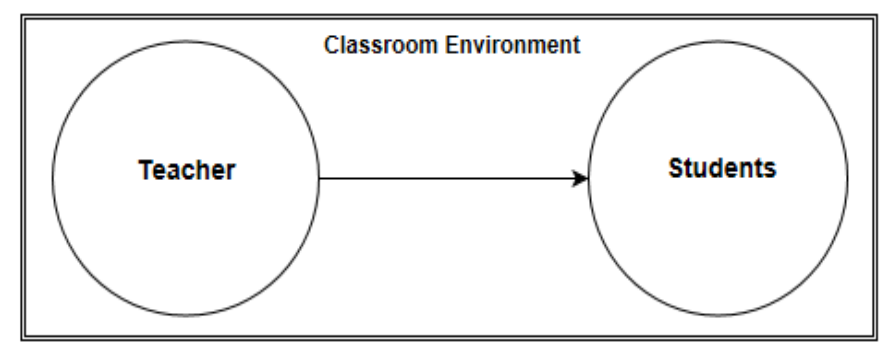

Fig. 1. Traditional teaching method, showing one-way information flow in a closed environment.

The authors in [41] discovered that students face difficulties understanding theories and concepts in SE courses when the method of teaching is straight forward and monotonous. This was supported by Grist and Myers [26], who stated that the traditional theory-based classroom approach is considered conventional and passive, which may result in dullness.

Course exit survey results have shown areas of deficiency related to real hands-on activities and practices. Statistical results for the 2014 - 2015 (35 students) and 2015 - 2016 (33 students) academic years in a software management course offered at Prince Sultan University are shown in Fig. 2. A scale from 1 (not satisfied) to 5 (fully satisfied) was used to indicate students' satisfaction with the following areas: 
1) Application of industry-strength tools and techniques for real software project planning.

2) Use of practical applications of real project management to formulate efficient strategies.

This course at Prince Sultan University is open to junior and senior students in SE, information systems, and computer science majors. The class covers all management aspects: scope, time, cost, communication, integration, resources, risks, quality, and procurement. A total of 27 students declared that they were somewhat satisfied or below in the $2014-2015$ academic year (Fig. 2). More than $77 \%$ were not satisfied with their management knowledge and skills due to the lack of industry practitioners. These survey results are in agreement with those obtained in [10]. Moreover, the authors of SWEBOK [16] mention and focus on the importance of management topics in the SE discipline. In addition, many SE curriculums [1]-[5] have ignored the SPM topic. This statement is well supported by [25], which stated that "the abstract nature surrounding the management of IT systems makes the concept difficult to teach in a classroom". The teaching pedagogical tendency should therefore emphasize the entire project life cycle using real projects/cases to successfully carry out the course outcomes.

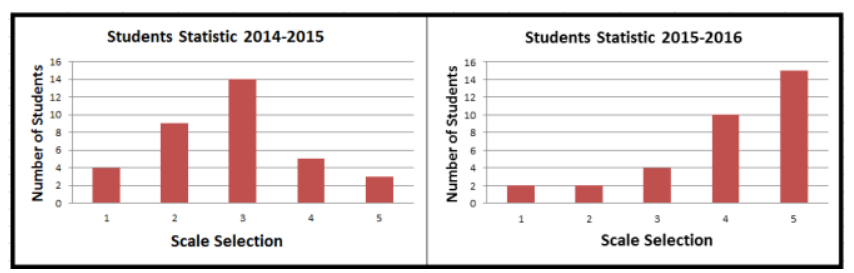

Fig. 2. Course exit survey statistics for two academic years in a software management course, 2014 - 2015 (35 students) and 2015 - 2016 (33

students). Traditional teaching methods were used in $2014-2015$, whereas a proposed tri-level teaching approach was followed in 2015 - 2016. Graphs indicate students' satisfaction $(1=$ not satisfied, $5=$ fully satisfied $)$ with their training in real-world software project planning and management.

In this paper, we present a tri-level teaching approach to ensure effective and meaningful learning in SPM courses. The proposed approach relies on a blended learning practice [27] grounded by guest-lecturing apprenticeships. The resulting environment provides learners with the necessary knowledge and skills, as well as an understanding of real management activities in the industry. Survey results for the $2015-2016$ academic year, when the proposed tri-level approach was used, indicated satisfaction from more than $75 \%$ of students (Fig. 2). The guest speaker's profile, qualification, and skills have an important impact on the teaching methodology success. To cover a real industry project timeframe, a blended learning model is used to cement what students do on their own and allow them to apply their knowledge to industry case studies presented by the guest speaker. The involvement of professionals from an industry environment in introducing and supervising students during their final project in a very industry-focused way changes students' perceptions about the SPM course and improves their management skills. Another important benefit of the proposed approach is to help students become familiar with the professional environment in an academic environment [8], including learning communication and operations practices. The blended learning pedagogy [27] has been shown to increase student engagement and significantly improve learning. To engage students in synthesis and analysis levels, it is very beneficial to combine regularlyscheduled, on-site classroom meetings with professional guest speakers and online learning activities using Moodle [42] and Calendly [41] to set meeting times and open discussions with the guest lecturers. The authors of [21] indicated the importance of the industry environment in providing core and advanced engineering knowledge and skills for the SE discipline. According to Jennings et al. [19], guest speakers can be used to enhance the sustainability of quality pedagogical methodologies and can offer real-world learning opportunities for students, as compared with traditional classroom learning methods. Hussein and Rolstadås [28] emphasized the importance of using multiple learning methods when delivering company tailored education programs.

The approach proposed herein attempts to bring industry environment into the classroom through guest lecturing, giving students the opportunity to be involved in industry projects and gain important work experience. This paper is organized as follows: Section II presents related works; Section III provides a brief introduction of the proposed teaching practice and environment; Section IV highlights the data analysis and results; and Section V concludes the paper.

\section{RELATED WORKS}

Many pedagogical strategies using guest lectures in SE education can be found in the literature. It is acknowledged that students learn more effectively when real project-based learning is incorporated into the learning process [7]. The authors in [10], [17] focus on the incorporation and selection of software projects in an industrial context to improve students' motivation and management skills. Both approaches [10], [17] showed promising results; however, the quality of the project output will depend not only on real project selection, but also on the execution environment and collaboration practices. Inviting a project manager to give a series of talks as a guest speaker from the industry and to supervise students enrolled in a SPM course meant to implement real activities can therefore have a good an impact on students' interest and management skills. Students in SE programs [6] appear to have a negative attitude about project management, and lack management and technical skills. SPM courses typically depend upon knowledge derived from several disciplines, including technology, computer science, engineering, sociology, and economics. In [24] authors proposed a quantitative methode for research purpose in writing their dissertation (research) proposals.

The authors of [18] proposed the use of guest lecturing to promote active learning through a constructivist approach [20]. Compared to the traditional environment, where students are often passive learners, the constructivist theory can yield remarkable benefits, adding value to the student learning experience. That study investigated the guest lecture approach in an online learning environment, however, where presentations are given using synchronous communications due to the difficulty of coordinating time between the speaker and students. As a result, students did not appear to benefit from guest speakers, due to the lack of face-to-face interaction. 
Moreover, such lectures require much time and effort to deliver.

Krishna [22] described an interesting teaching method for project management using simulation. Project management simulation is used for what-if analysis, helping managers promote effective decision-making in real projects. It is an interactive learning group activity, where students try to solve real-world projects involving factors such as scope, time, schedule, and resources [23]. Simulation has been appropriated for many disciplines, including health and the military, although the technology can become confining for some junior students. Bassem [40] proposed a similar approach to ours, based on a blended teaching approach with a company presentation component. He demonstrated in detail how blended learning practices can be applied in order to create a learning environment that facilitates involvement and engagement of learners, providing learners with a sound understanding of project complexity. The aim of the invited guest speaker is to give the students some practical insights. The incorporation of games can allow students to emphasize fun and ignore serious learning. Additionally, participation requires students to invest energy in all phases of the learning process.

Many other teaching approaches for project management based on games are proposed in the literature. Such approaches encourage exploration and trial-and-error actions with the possibility of instant feedback, therefore stimulating curiosity and learning. The authors in [29] described the theoretical foundation of games as a teaching approach. The focus was on the importance of direct experience, reflective observation, and appropriate feedback in a continuous process of goal-directed action [30]. The authors showed that summative assessments, such as assignments, case studies, and exams, provide training and knowledge, whereas games offer direct experimentation and observation.

Many works [31]-[35] have reported games as an efficient learning approach in project management courses. Some of these proposed approaches [31], [32] rely heavily on a computer environment, whereas Klassen and Willoughby [33], Hood [34], and Bohn and Lynch-Caris [35] reported on classroom-based simulation games using a medium other than computers. An effectiveness study of the game learning approach in management courses remains to be verified. In a typical approach, the project is first modelled in a software tool along with uncertain variables. A simulation is then run to check the different possible outcomes and their probability as a result of different inputs for the uncertain variables. Pfahl et al. [36], [37] conducted several experiments to measure the effectiveness of game teaching approaches. They concluded that games are a very useful approach for learning about issues in SPM. Other works [38], [39] concerning learning behaviors, however, have led us to infer that there is no emphasis on teaching skills or content, only a focus on social behavior. In addition, skills concerning computation technology are a necessity for all learners.

\section{Proposed Teaching Practice And EnVIRONMENT}

In this section, we present our environment study and the detailed implementation of our proposed teaching approach.

\section{A. Study Context and Environment}

This study took place in a SPM course at Prince Sultan University, Saudi Arabia, during the academic years 2014 $2015,2015-2016$, and 2016 - 2017. The target group of the course included full-time university students working on a degree in Software Engineering, Information Systems, or Computer Science. The course used two different teaching approaches. In 2014 - 2015, a traditional classroom was used, whereas in 2015 - 2016 and 2016 - 2017, a proposed tri-level teaching approach was applied. Effectiveness (knowledge, skills) and students' motivation were analyzed following each approach.

The total number of students enrolled in the course was 35 students in 2014 - 2015, 33 students in 2015 - 2016, and 22 students in 2016 - 2017. The course prerequisites are IS241: Database Management and IS231: System Analysis and Design. The purpose of the proposed approach was to expose students to the industry background in an academic environment, where appropriate real-world decisions based on case studies would be supervised and evaluated by professionals throughout the semester.

In this study, we used a graded rubric [13], [14] approach and an exit course survey to measure the learning outcomes and students' performance. Course learning outcomes were mapped to program learning outcomes and evaluated. Peer observation was also implemented to evaluate the efficiency of the proposed teaching method, based on the Higher Education Academy peer review process [12].

\section{B. The Proposed Tri-Level Teaching Approach}

Several instructional methods were used in the course. In addition to classroom lectures and other supporting materials, such as handouts, lectures notes, exercises, papers, written project reports, and quizzes, the course relied heavily on guest speakers to demonstrate and discuss real industry projects. The proposed tri-level teaching approach is presented in Fig. 3. We believe that much of the effective teaching that results from this approach is due to the fact that the students are supported by both the teacher and guest speakers, and both classroom and industry environments are well integrated into the whole course experience.

Students apply their knowledge and skills in real-world industry case studies and interact with professionals in the management field and real clients. To facilitate this, we move from the traditional academic environment to an industrial environment. The overall idea is to expose students to the industry background in an academic environment.

The approach implementation highlights the relevance of course content by pointing out its significance in the real world and introducing real hands-on case-studies that are presented, supervised, and evaluated by an experienced project manager from the industry. Material relevance and real hands-on activities are key determinants of student motivation. If students feel motivated, they are more likely to take an active role in their own learning, which in turn can lead to better knowledge acquisition. 


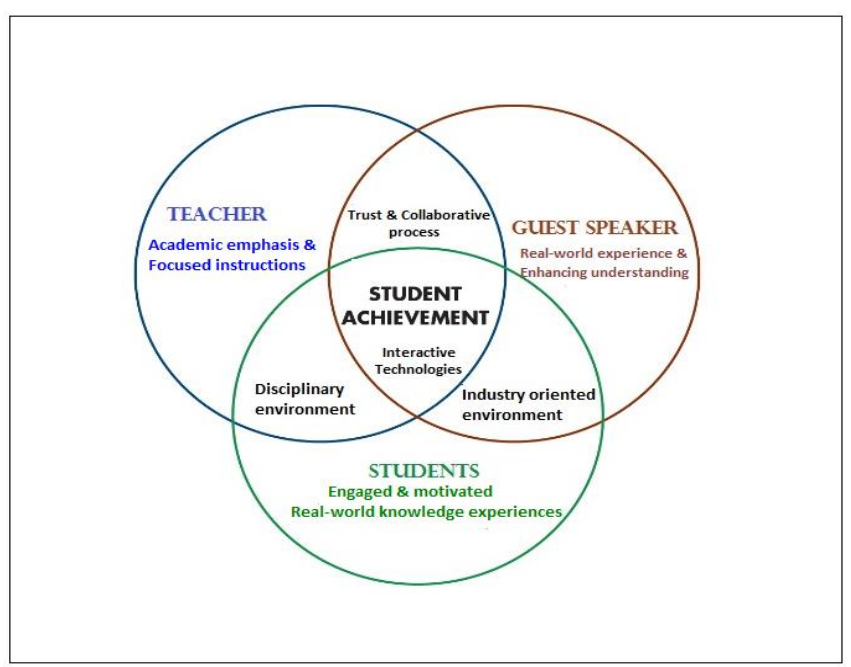

Fig. 3. Proposed tri-level teaching practice.

With the agreement of the guest speaker, a peer observation was completed during this visit. A screenshot of the observation report is shown in Fig. 5. The observation focused on students' interest, motivation, and participation. The observation agenda included the following items:

- Observe student engagement during the case study activity Relates information to future, practical (realworld) application Shares up-to-date info in field.

- Observe student motivation.

- Observe guest speaker-student interaction Students respond positively and/or engage effectively with guest speaker questions.

The purpose of this research action was to examine the impact of both the guest speaker and the use of a real case study on students' interest and motivation in the SPM course.

The majority of SE students hope to enter the professional management field in some way. Professional guest speakers can motivate students by linking their course content to students' intended professions, and by pointing out how the skills and knowledge gained in class will help them after they graduate. The instructional components of the proposed trilevel approach are:

Lecture: These are regular face-to-face lectures conducted using different teaching aids, such as PowerPoint presentations and notes taken in the class. All materials are available on the LMS course web site.

Textbook: Essential Scrum: A Practical Guide to the Most Popular Agile Process

Author: Kenneth S. Rubin

Publisher: Addison Wesley Professional

Summative Assessment: The purpose of summative assessment is to evaluate student learning at the end of an instructional unit by comparing it against some standard or benchmark. In this course, we used assignments, quizzes, group projects, case studies, a midterm exam, and a final exam.
Formative Assessment: The purposes of the formative assessment are to monitor student learning and target areas that require work. We used online discussion and a forum.

LMS Moodle [43]: This is an educational software helping teachers and trainers create and deliver effective online learning environments used by millions world-wide. We used Moodle as a learning management system to upload all course materials, announcements, assessments, etc.

Guest Speaker: "Mr. Eng”, a functional project manager in the telecommunication industry, was invited as a guest speaker to offer three talks to the students and present real case studies with the intention of improving their management skills [8], [9]. Continuous feedback concerning the case study implementation was given by the guest speaker to the students. As an instructor, I prepared the students before each visit and made sure we covered the discussed materials before the guest lecture. This further stimulated deep conversations concerning the topic and avoided awkward silence during the session. Three sessions were scheduled, and each session was structured to engage the students in thinking and reasoning throughout the class period.

The outline of the talk for the first visit (week three) was as follows: 1) an introduction to break the ice; 2) an open discussion about the distinction between management and administration, presenting both theories from Mary Follett and Sheldon [11]; 3) an overview of the project management process with a focus on the ways in which project management may vary significantly from one organization to another; and 4) "Mr. Eng" presented a real case-study about managing the development of a new billing system for the SFR Telecom Company. This case study was used throughout the semester, beginning with the preparation of the business case and project charter, followed by the development of work breakdown structure, and finally the implementation of the whole project using Microsoft Project.

The outline of the talk for the second visit (week seven) was as follows: 1) students presented a progress report about the case study discussed in the first visit; 2) "Mr. Eng" presented a fairly easy-to-implement project management process using the triple-constraint model and Microsoft Project; and 3) an open discussion occurred concerning problems faced in real projects, such as budget, time, and the closing process. Students practiced many approaches to shrink resources and tighten deadlines, in order to make project management more important and attract students to the management field.

The outline of the last visit (week 15) involved students presenting their final product, as expected by following the planning schedule. The final presentation occurred at the end of the semester after we had covered all materials necessary to complete the project successfully. The project assessment scheme was based $50 \%$ on the guest speaker and $50 \%$ on the course instructor. "Mr. Eng" then gave constructive feedback to the students.

\section{ANALYSIS AND OBSERVATION}

Typically, students enrolled in SE possess excellent knowledge of computer and information sciences, but their 
skills are weak in the field of business practice and management. There is therefore a need to focus on the subject of management and avoid repeating knowledge related to software development that has already been learned.

It important to mention that SPM courses include copious amounts of material for students to consume due to the numerous definitions and basic concepts in management that must be covered, and the fact that no business knowledge is acquired frustrates and discourages students. As a first step, we put extensive effort into lessening the amount of material to an appropriate volume and reducing the required texts.

Students had difficulties applying what they learned in a real-world context (Fig. 2). It is therefore important for students to clearly see how their coursework connects to their interests and how to apply their management knowledge to real-life problems. The program learning outcomes and course learning outcomes (CLO) for the proposed course are mapped in Fig. 4. Special focus was placed on CLO 6.

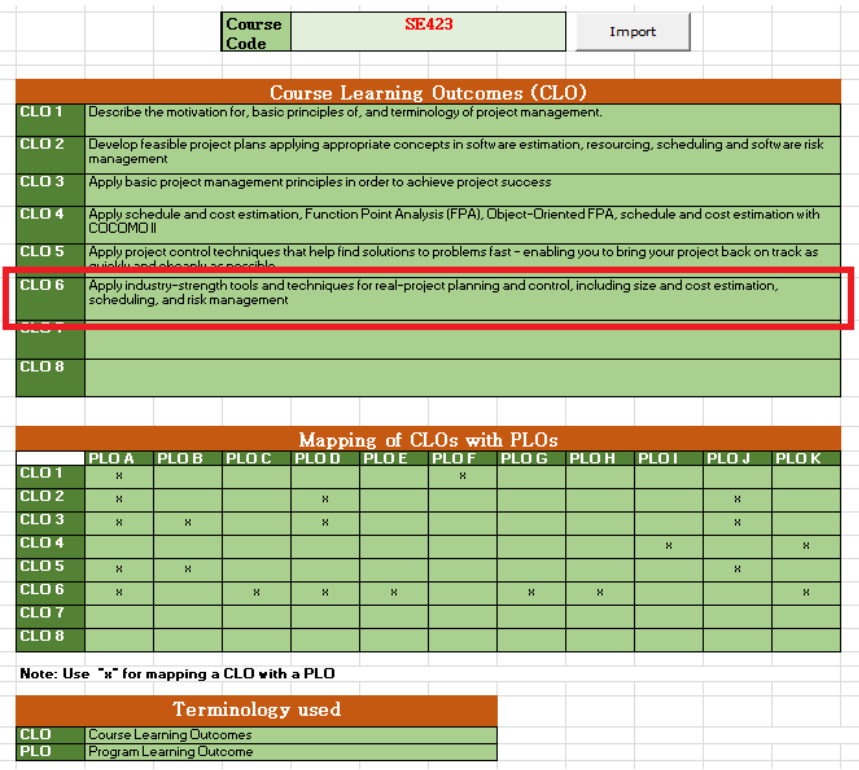

Fig. 4. Mapping of program learning outcomes (PLO) and course learning outcomes (CLO) for software project management education.

The proposed tri-level teaching practice strategy is adapted to bring industry to the classroom. The authors of [8], [9] showed the importance of using decision case studies in engineering education to expose students to real-world issues with which they may be faced.

\section{A. Data Collection}

Information collected from exit course surveys (Fig. 2) showed that students face some difficulties in applying their learning knowledge to real-life practice projects. We used a grade-based rubric system implemented in our department to automatically convert grades to rubrics. This means that CLO achievement was measured based on the number of students whose achievements were categorized as "accomplished expectations", based on the rubrics. Four levels with three criteria were used for this rubric (Fig. 5).

\begin{tabular}{|c|c|c|c|}
\hline \multicolumn{3}{|c|}{ BE } & Below Expectations \\
\hline \multicolumn{3}{|c|}{$\mathrm{DE}$} & Developing Expectations \\
\hline \multicolumn{3}{|c|}{ ME } & Meeting Expectations \\
\hline \multicolumn{3}{|c|}{$\mathrm{AE}$} & Accomplished Expectations \\
\hline & \multicolumn{3}{|c|}{ Section's Satisfaction } \\
\hline 0 & 0.00 & BE & $\begin{array}{l}\text { Less than } 60 \% \text { of students are } \\
\text { achieving the Satisfactory level } \\
\text { (ME) or above }\end{array}$ \\
\hline 1 & 60.00 & DE & $\begin{array}{l}60 \% \text { to } 69 \% \text { of students are } \\
\text { achieving the Satisfactory level } \\
\text { (ME) or above }\end{array}$ \\
\hline 2 & 70.00 & ME & $\begin{array}{l}70 \% \text { to } 89 \% \text { of students are } \\
\text { achieving the Satisfactory level } \\
\text { (ME) or abovic }\end{array}$ \\
\hline & 90.00 & $\mathbf{A E}$ & $\begin{array}{l}90 \% \text { or more of students are } \\
\text { achieving the Satisfactory level }\end{array}$ \\
\hline
\end{tabular}

Fig. 5. Rubric levels used to assess achievement of course learning outcomes.

Equation (1) shows the details of the rubric calculation:

$$
R=\frac{\sum_{i=1}^{N}\left(m_{i}-\min _{i}\right)}{\sum_{i=1}^{N}\left(\max _{i}-\min _{i}\right)}
$$

Where $\mathrm{m}_{\mathrm{i}}$ is the grade for the $\mathrm{i}^{\text {th }}$ criterion, $\min _{\mathrm{i}}$ is the minimal possible grade for the $i^{\text {th }}$ criterion, $\max _{i}$ is the maximal possible grade for the $i^{\text {th }}$ criterion, and $\mathrm{N}$ is the number of criteria used to compute the rubric. The formula per assessment is:

(Number of students achieved AE and ME) /

(Total number of assessed students)

Statistical results showed "Below Expectations" for the academic year 2014 - 2015, due to the lack of practical work (Fig. 6). The aggregation of CLO 6 using both direct and indirect assessments was below expectations (53\%).

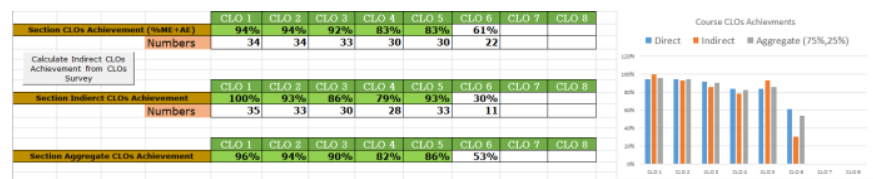

Fig. 6. Rubric results for the academic year 2014-2015.

Similar data were collected during the academic year 2015 - 2016 to observe the impact of the proposed approach using real hands-on activities from the industry. The rubric analysis showed interesting results of "Meeting Expectations" (Fig. 7).

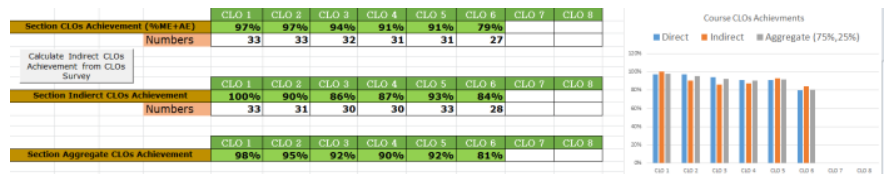

Fig. 7. Rubric results for the academic year $2015-2016$.

Based on the rubric analysis, the impacts of the guest speaker and the use of real case studies were clearly reflected in the students' outcomes. Comparing Fig. 7 to Fig. 6, we achieved an improvement of approximately $40 \%$. The number of students increased from 11 to 27 students. Similar results 
were found in 2016 - 2017, but these are not included in this paper due to space constraints.

\section{B. Data Analysis}

The rubric completed in the academic year $2014-2015$ showed that students faced difficulties applying industry tools to real projects. Additionally, students complained about the lack of practical tools, such as project planners and practical examples of management using Microsoft Project.

After applying the proposed tri-level teaching approach, the results collected in the academic year 2015 - 2016 showed an improvement in CLO 6, as expected. Student cohorts and rubrics showed that students' experience and motivation improved by approximately $40 \%$. In addition, this approach enhanced the teaching pattern quality, adapting new tools on the market and being reflected in the course content for the following semester.

Students gained professional practice to achieve excellence in their future professional lives. The most problematic issue in this strategy is how to find a guest speaker who possesses specific experience, and is willing to do student follow-up case studies and offer a series of talks over the course of the semester.

The hands-on activities using a real case study proposed and supervised by an invited guest speaker overcame the disadvantages mentioned in [10], [17]. Students were confronted with new and very challenging ideas by professionals from the industry.

Survey and rubric results completed in 2015 - 2016 and 2016 - 2017 showed better outcomes compared to results collected in previous semesters. Furthermore, external peer observation confirmed the benefit of the guest speaker and varying viewpoints in classroom. "Mr. Eng" has strong experience in project management, as well as good teaching experience, and was easily able to draw the students' attention. The importance of peer review is that it presented an independent opinion concerning the proposed teaching approach being adopted in SPM courses at Prince Sultan University.

\section{CONCLUSION AND FUtURE ACTIONS}

Overall, the use of the proposed tri-level teaching approach improved students' motivation and interest in the software management field. Having an experienced project manager from the industry field as a guest speaker, to offer a series of talks and supervise students in their final project, changes the environment from a traditional academic environment to an industry environment, discharging students from classroom routines. Students show interested behavior and are motivated during the whole semester. Exit surveys and grade-based rubric calculations showed remarkable achievement compared to previous years when the course was delivered using a traditional classroom approach.

Inviting a guest speaker to the classroom switches things up from the normal traditional routine, giving students an opportunity to interact with professionals and apply their learning in real case studies proposed by the guest speaker. Students receive the opportunity to engage in real hands-on activities with their peers. Additionally, the external peerreview report recommended this move. The field of engineering requires effective professional activities in order for engineers to feel comfortable with their capacity to be leaders or managers. The educational approach proposed here could also be implemented for school children, to develop future engineering students.

\section{ACKNOWLEDGMENT}

The authors would like to thank Prince Sultan University (PSU) and Al Imam Mohammad Ibn Saud University for supporting this work.

\section{REFERENCES}

[1] Software Project management Course Specification available online (2015)

http://infosci.otago.ac.nz/assets/courseoutlines/2014/semesterone/seng301-s1-2014.pdf

[2] Software Project management Course Specification available online (2016) https://is.stuba.sk/katalog/syllabus.pl?predmet=277020

[3] Software Project management Course Specification available online (2015)

http://www.tamuc.edu/academics/cvsyllabi/syllabi/201420/21007.pdf

[4] Software Project management Course Specification available online (2016) http://dox.utdallas.edu/syl29333

[5] Software Project management Course Specification available online (2015)

https://cs.uwaterloo.ca/ apidduck/se362/Lectures/1intro.pdf

[6] Software Engineering Standards Committee of the IEEE Computer Society "IEEE Standard for Software Project Management Plans".

[7] Bonwell C C and Eison J A ."Active Learning: Creating Excitement in the Classroom". ASHE-ERIC Higher Education Report No. 1. The George Washington University, School of Education and Human Development, Washington, DC.1991

[8] R. Mustoe, and C. Croft; "Motivating Engineering Students by Using Modern Case Studies" European Journal of Engineering Education. Vol. 15, Issue: 6 pp: 469-476, 1999.

[9] P. Raju, and C. Sanker; "Teaching Real-World Issues through Case Studies". Journal of Engineering Education. Vol. 88, issue. 4, pp: 501-508, 1999.

[10] S. Karunasekera, and K. Bedse; "Preparing Software Engineering Graduates for an Industry Career". Software Engineering Education \& Training, 2007. CSEET '07. 20th Conference on, pp:97-106,2007.

[11] Chapter book: Management Principles and Practices. "Chapter 1: nature and Scope of Management" http://www.newagepublishers.com/samplechapter/000951.pdf

[12] Peer Review Form available online 2015: https://www.heacademy.ac.uk/resource/peer observation-teaching

[13] S.McKenzie, and G.Wood-Bradley; "Using rubrics in IT: Experiences of assessment and feedback at Deakin University". Teaching, Assessment and Learning (TALE), 2014 International Conference on, pp: $474-479,2014$

[14] S. Barney, M. Khurum, K. Petersen, and M. Unterkalmsteiner;''Improving Students With Rubric-Based SelfAssessment and Oral Feedback". Education, IEEE Transactions on Vol.55, Issue. 3 , pp:319-325, 2011.

[15] P. Naur and B. Randell; Software Engineering: Report of a conference sponsored by the NATO Science Committee, Garmisch, Germany, 7-11 Oct. 1968, pp: 231

[16] The Software Engineering Body of Knowledge (SWEBOK) available online (2015): http://www.computer.org/web/swebok/v3

[17] S. Hanna, J. Hayat, A. Almasalmeh, and A. Fawze; "Reducing the Gap between Software Engineering Curricula and Software Industry in Jordan" Journal of Software Engineering and Applications, Vol 7, pp: 602-616, 2014 
[18] Lei Li Rong and Guo A student-centered guest lecturing: A constructivism approach to promote student engagement, Journal of Instructional Pedagogies - Volume 15 October, 2015

[19] Jennings, G., Kensbock, S., \& Kachel, U. (2010). Enhancing 'Education About and For Sustainability' in a Tourism Studies Enterprise Management Course:

[20] Kolb, D. (1984). Experiential Learning: Experience as the Source of Learning and Development. Englewood Cliffs, NJ: Prentice Hall.

[21] R.B. Vaughn ; J. Carver The Importance of Experience with Industry in Software Engineering Education. 2006 Software Engineering Education and Training Workshops, 2006. CSEETW '06. 19th Conference on

[22] Krishna Kumar Innovative Teaching Methods in Management International Journal of ManageMent \& BusIness studies Vol 4, Issue 3, 2014.

[23] Neal. D.J.,"Group competitiveness and cohesion in a business simulation", Simulation \& gaming, Vol. 28, Issue 4, 1997.

[24] J. W. Cresswell, Research Design Qualitative, Quantitative, and Mixed Methods Approaches, SAGE Inc. USA, 2009

[25] A.Tatnall and G. Reyes. "Teaching IT Project Management to Postgraduate Business Students: A Practical Approach”, Journal of IT Education, Vol 4,.2005.

[26] Geist, D.B.; Myers, M.E. Pedagogy and project management: Should you practice what you preach. Comput. Small Coll 2007, 23, 202-208.

[27] M. Wild, White Paper Blending Learning - what's in the mix? Nine Lanterns. Available www.ninelanterns.com.au/files/9L/pdf/Blended-Learning.pdf

[28] B.Hussein, and A. Rolstadås, Hybrid learning in project management: Potentials and challenges. In Frontiers of project management research and application: Proceedings of the PMI Research Conference, Seattle, WA, USA, 14-17 July 2002; Project Management Institute: Pennsylvania, PA, USA, 2002; pp. 451-455.

[29] D. Kolb, Experiential learning: Experience as the source of learning and development. Prentice-Hall: Englewood Cliffs, NJ, USA, 1984; p. 256.

[30] B. Hussein, Simulation games for project management training and research- litrature review. In Proceedings of the 11th special intrest group on workshop on experimental interactive learning in industrial management, Bremen, Germany, 21-23 May 2007; Thoben, K.-D., Hauge, J.B., Smeds,
[31] J. Cano, and M. Saenz, Project management simulation laboratory: Experimental learning and knowledge acquisition. Prod. Plan. Control 2003, 14, 166-173.

[32] A. Martin, A simulation engine for custom project management education. Int. J. Proj. Manag. 2000, 18, 201-213.

[33] J. Klassen, and K. Willoughby, In Musikfest: An in-class Project Management Game; Decision Sciences Institute: Washington, DC, USA, 2003; pp. 811-816.

[34] D. Hood, Teaching software project management using simulations. In Proceedings of the 11th Annual SIGCSE Conference on Innovation and Technology in Computer Science Education, ITiCSE Italy, 2006;

[35] A. Bohn, and C. Lynch Increasing project management skills using role-playing simulations. IEE Annu. Conf. Proc. 2011, 1-7. Avialable online: (accessed on $11 \quad$ February 2017).

[36] Pfahl, D.; Laitenberger, O.; Ruhe, G.; Dorsch, J.; Krivobokova, T. Evaluating the learning effectiveness of using simulations in software project management education: Results from a twice replicated experiment. Info. Softw. Technol. 2004, 46, 127-147.

[37] Pfahl, D.; Laitenberger, O.; Dorsch, J.; Ruhe, G. An externally replicated experiment for evaluating the learning effectiveness of using simulations in software project management education. Empir. Softw. Eng. 2003, 8, 367-395.

[38] Randel, J.M.; Morris, B.A.; Wetzel, C.D.; Whitehill, B.V. The effectiveness of games for educational purposes: A review of recent research. Simulation \& Gaming 1992, 23, 261- 276.

[39] S. De Freitas, and M. Griffiths. Online gaming as an educational tool in learning and training: Colloquium. Br. J. Educ. Technol. 2007, 38, 535-537.

[40] A. Bassam and A. Hussein. A Blended Learning Approach to Teaching Project Management: A Model for Active Participation and Involvement: Insights from Norway, Journal education sciences, Vol 5, issue 2, pp 104-125, 2015

[41] C. Jianguo ; L. Huijuan, A. Lixin An , and z. Yongxia. "Exploring teaching methods in software engineering education". Computer Science \& Education, ICCSE 4th International Conference on. 2009

[42] Calendy website: https://calendly.com/ . (accessed on 11 February 2017).

[43] S. Kumar; A. Kumar Gankotiya; and D. Kamlesh. "A comparative study of moodle with other e-learning systems" Electronics Computer Technology (ICECT), 2011 3rd International Conference on 